\title{
Evaluation of the Bonding Strength between Various Dental Zirconia Models and Human Teeth for Dental Posts through In Vitro Aging Tests
}

\author{
Shih-Chieh Lin ${ }^{1}$, Wei-Chun Lin ${ }^{2}\left(\mathbb{D}\right.$, Tai-Chia Hu ${ }^{3}$, Min Yan ${ }^{1,4}, *$ and Cheng-Ming Tang ${ }^{1,4, *(D)}$ \\ 1 Graduate Institute of Oral Science, Chung Shan Medical University, Taichung 40201, Taiwan; \\ lsch519@gmail.com \\ 2 School of Dental Technology, College of Oral Medicine, Taipei Medical University, Taipei 11031, Taiwan; \\ weichun1253@tmu.edu.tw \\ 3 Department of Dental Technology, Shu-Zen Junior College of Medicine and Management, \\ Kaohsiung 82144, Taiwan; p105083@ms.szmc.edu.tw \\ 4 Department of Dentistry, Chung Shan Medical University Hospital, Taichung 40201, Taiwan \\ * Correspondence: yan@csmu.edu.tw (M.Y.); ranger@csmu.edu.tw (C.-M.T.)
}

Citation: Lin, S.-C.; Lin, W.-C.; Hu, T.-C.; Yan, M.; Tang, C.-M. Evaluation of the Bonding Strength between Various Dental Zirconia Models and Human Teeth for Dental Posts through In Vitro Aging Tests. Coatings 2021, 11, 1017. https:// doi.org/10.3390/coatings11091017

Academic Editor: Jasmina Primožič

Received: 22 July 2021

Accepted: 23 August 2021

Published: 25 August 202

Publisher's Note: MDPI stays neutral with regard to jurisdictional claims in published maps and institutional affiliations.

Copyright: (c) 2021 by the authors. Licensee MDPI, Basel, Switzerland. This article is an open access article distributed under the terms and conditions of the Creative Commons Attribution (CC BY) license (https:// creativecommons.org/licenses/by/ $4.0 /)$

\begin{abstract}
In dentistry, root canal treatment reduces support of the tooth, making it necessary to insert a cylindrical body into the treated tooth to strengthen the crown. In the past, metal or fiberglass was often used. However, metal is too different in color from teeth, so the esthetics are poor, and fiberglass is not as strong as metal. Therefore, an alternative is zirconia, which has the characteristics of high light transmittance, esthetics, good biocompatibility, and high breaking strength. The surface morphology and composition of zirconia ceramics are the key to their bond strength with teeth. Therefore, in this study, the surface characteristics of different brands of zirconia commonly used in clinical practice were evaluated in terms of their surface morphology and surface elements. The surface was modified by sandblasting, and its effect on the bonding strength was discussed. Finally, the stability of the material was evaluated through artificial aging. The results showed that the surface roughness of the zirconia specimens increased after sandblasting, whereas the surface microhardness decreased. The shear test results showed that the 3D shape of the zirconia surface could help improve the bonding strength. The bonding strength of DeguDent increased the most after sandblasting. After 20,000 cycles of aging treatment, the shear strength of each specimen decreased. Field emission scanning electron microscopy results showed that the adhesive remained intact on the surface of zirconia, indicating that adhesion failure occurred between the adhesive and the teeth. This confirms that sandblasting can improve the bonding strength of zirconia. Based on the results obtained, it was concluded that the surface roughness of zirconia is the main factor affecting the bond strength.
\end{abstract}

Keywords: zirconia; dental post; aging test; bonding strength; dental

\section{Introduction}

Dentists insert a "post" into the root of a patient's tooth after root canal treatment to support the crown. The conventional post materials used in dentistry are metal and fiberglass. However, metal materials have shortcomings such as unnatural color, poor light transmittance, and the metal color being exposed at the gums [1]. Although fiberglass is more esthetically pleasing in color than metal, it is not as strong [2]. Therefore, other materials are sought as alternatives. Zirconia is one such material that has excellent mechanical properties, chemical stability, and esthetics [3] and is being used in clinical practice as a post material. Prefabricated zirconia posts have been shown to reduce the time and cost of treatment. The zirconia post itself is a high-density ceramic that results in high $X$-ray image contrast. Therefore, zirconia posts can help physicians identify recurrent dental caries [4]. However, the main reason for the failure of post retention is poor adhesion [5]. Therefore, clinicians must understand the bonding strength and retention conditions of 
different cylindrical post specimens to reduce the risk of root fractures [6]. Despite this, the bonding of zirconia with the teeth remains a major clinical challenge. The solutions are to increase the adhesive strength of zirconia by changing the type of adhesive or applying surface treatment [7-9].

Surface treatments for zirconia can be divided into two types: physical and chemical. Currently, common methods include sandblasting [10-18], acid etching (hydrofluoric acid) $[11,19,20]$, silicon dioxide coating sandblasting [10,20-23], Er: YAG laser irradiation $[11,13,24]$, and the application of coatings containing metal [13]. In addition, it is reported in the literature that the surface roughness can be increased with a proper milling strategy before sintering the zirconia or glass-ceramics [25-27].

In these methods, the ceramic surface area is increased to obtain a rough surface and create the contact area and micropores, or chemical bonding conditions are employed to improve the retention between the ceramic and the adhesive. For example, hydrofluoric acid can be used to corrode or chemically modify the ceramic surface, thereby strengthening the bonding between zirconia and the adhesive. However, simply using acid etching to increase the bond strength between zirconia and the resin adhesive is insufficient. Sandblasting the surface of zirconia using alumina particles with a silicone coating causes rubbing and generates high temperatures. The silicone on the surface of the alumina particles then adheres to the zirconia surface and undergoes silane treatment $[20,22]$. This process can improve the chemical bonding between zirconia and resin.

The bonding between a dental restoration and a tooth determines the stability of the prosthesis. The adhesive will have poor stability because of the dynamic oral environment (temperature, chemistry, and mechanics). To make the test results of the material more consistent with the clinical results, artificial aging tests are conducted along with the bonding strength test. In this method, the test material is placed in an environment similar to the oral cavity, and a thermal cycler is used to circulate the material at extremely high and low temperatures for a fixed duration. This helps simulate the alternating hot and cold environments in the mouth as an assessment of the long-term usability of the material $[17,22,23]$.

The performance and strength of a dental zirconia root stem are determined by the bond strength between the ceramic and the tooth veneer. Currently, there is no optimal treatment procedure for bonding the zirconia post surface and teeth. The surface properties of zirconia, which is used commonly in clinical practice, were analyzed in this study. The roughness, hardness, and grain size of zirconia were compared and sandblasting was applied for surface modification to observe whether these conditions affected the adhesion strength. We simulated the environment of the human oral cavity by varying the humidity and temperature and then conducted an aging test with 20,000 hot and cold cycles to evaluate the bonding strength. The influence of temperature on the bonding force between zirconia and the adhesive is discussed. The material characteristics of each group of zirconia specimens were analyzed and compared with the results of the sandblasted surface to obtain the best adhesion effect. The results of this study could contribute to restoration after root canal treatment with zirconia posts.

\section{Materials and Methods}

\subsection{Preparation of Zirconia}

In this study, the zirconia samples were divided into five groups based on the name of the disc producer (Metoxit, NexxZr, Upcera, Dentaswiss, DeguDent), with each group containing a total of 10 test pieces (Table 1). Each zirconia disc was cut into a fixed-size test piece $(15 \mathrm{~mm} \times 10 \mathrm{~mm} \times 2 \mathrm{~mm})$ through computer-aided design/computer-aided manufacturing (CAD/CAM, Motion2, Amann Girrbach, Kobrach, Austria). The mill diameters used were Lyra conical tool $\varnothing 0.3 \mathrm{~mm}, \varnothing 0.6 \mathrm{~mm}, \varnothing 1.0 \mathrm{~mm}$, and $\varnothing 2.5 \mathrm{~mm}$ (Amann Girrbach). Subsequently, each test piece was placed in a sintering furnace and sintered at $1450{ }^{\circ} \mathrm{C}$ for a dwell time of $1 \mathrm{~h}$ (Figure 1 ). 
Table 1. Materials, Codename, Characteristic, and Composition of all tested materials.

\begin{tabular}{|c|c|c|c|c|}
\hline Name & Codename & $\begin{array}{l}\text { Coefficient of Thermal } \\
\text { Expansion } \\
\left(25-500^{\circ} \mathrm{C}\right)\end{array}$ & $\begin{array}{l}\text { Flexural Strength } \\
\text { (Mpa) }\end{array}$ & $\begin{array}{l}\text { Composition } \\
\text { (Wt.\%) }\end{array}$ \\
\hline $\begin{array}{c}\text { DeguDent } \\
\text { Cercon ht Disk }\end{array}$ & DeguDent & $10.5 \times 10^{-6} \mathrm{~K}^{-1}$ & 1200 & $\begin{array}{c}\text { Zirconium oxide, Yttrium } \\
\text { oxide } 5 \% \text {, Hafnium oxide }<3 \% \text {, } \\
\text { Aluminium oxide and Silicon } \\
\text { oxide }<1 \%\end{array}$ \\
\hline Ceramic Blanks System & Metoxit & $11.2 \times 10^{-6} \mathrm{~K}^{-1}$ & 1250 & $\begin{array}{c}\mathrm{ZrO}_{2}+\mathrm{HfO}_{2}+\mathrm{Y}_{2} \mathrm{O}_{3}>99.5 \% \\
\mathrm{Y}_{2} \mathrm{O}_{3} 5.2 \%, \mathrm{Al}_{2} \mathrm{O}_{3}<0.05 \% \text { and } \\
\text { Other Oxides } \leq 0.5 \%\end{array}$ \\
\hline $\begin{array}{l}\text { NexxZr T Dental } \\
\text { Zirconia Blanks }\end{array}$ & NexxZr & $10 \times 10^{-6} \mathrm{~K}^{-1}$ & 1150 & $\begin{array}{c}\mathrm{ZrO}_{2}+\mathrm{HfO}_{2}+\mathrm{Y}_{2} \mathrm{O}_{3}>99.5 \\
\mathrm{ZrO}_{2} 91.6, \mathrm{Y}_{2} \mathrm{O}_{3}, \mathrm{HfO}_{2}, \mathrm{Al}_{2} \mathrm{O}_{3} \\
<0.15 \text { and Other Oxides }<0.2\end{array}$ \\
\hline $\begin{array}{l}\text { Upcera Dental } \\
\text { Zirconia Blank }\end{array}$ & Upcera & $10.5 \times 10^{-6} \mathrm{~K}^{-1}$ & 1200 & $\begin{array}{c}\mathrm{ZrO}_{2}+\mathrm{HfO}_{2}+\mathrm{Y}_{2} \mathrm{O}_{3} 99.6 \% \\
\mathrm{Y}_{2} \mathrm{O}_{3} 5.2 \%, \mathrm{Al}_{2} \mathrm{O}_{3} 0.2-0.5 \% \\
\text { and Other oxide }<0.2 \%\end{array}$ \\
\hline $\begin{array}{l}\text { Dentaswiss Zirconia } \\
\text { Disc-Translucent }\end{array}$ & Dentaswiss & $10.5 \times 10^{-6} \mathrm{~K}^{-1}$ & 800 & $\begin{array}{c}\mathrm{ZrO}_{2}+\mathrm{HfO}_{2}+\mathrm{Y}_{2} \mathrm{O}_{3} 99 \% \\
\mathrm{Y}_{2} \mathrm{O}_{3} \leq 6.0 \%, \mathrm{Al}_{2} \mathrm{O}_{3} \leq 0.5 \% \\
\text { and Other oxide } \leq 0.5 \%\end{array}$ \\
\hline
\end{tabular}

The above data sources are all product manuals. Flexural strength is three-point flexural testing.

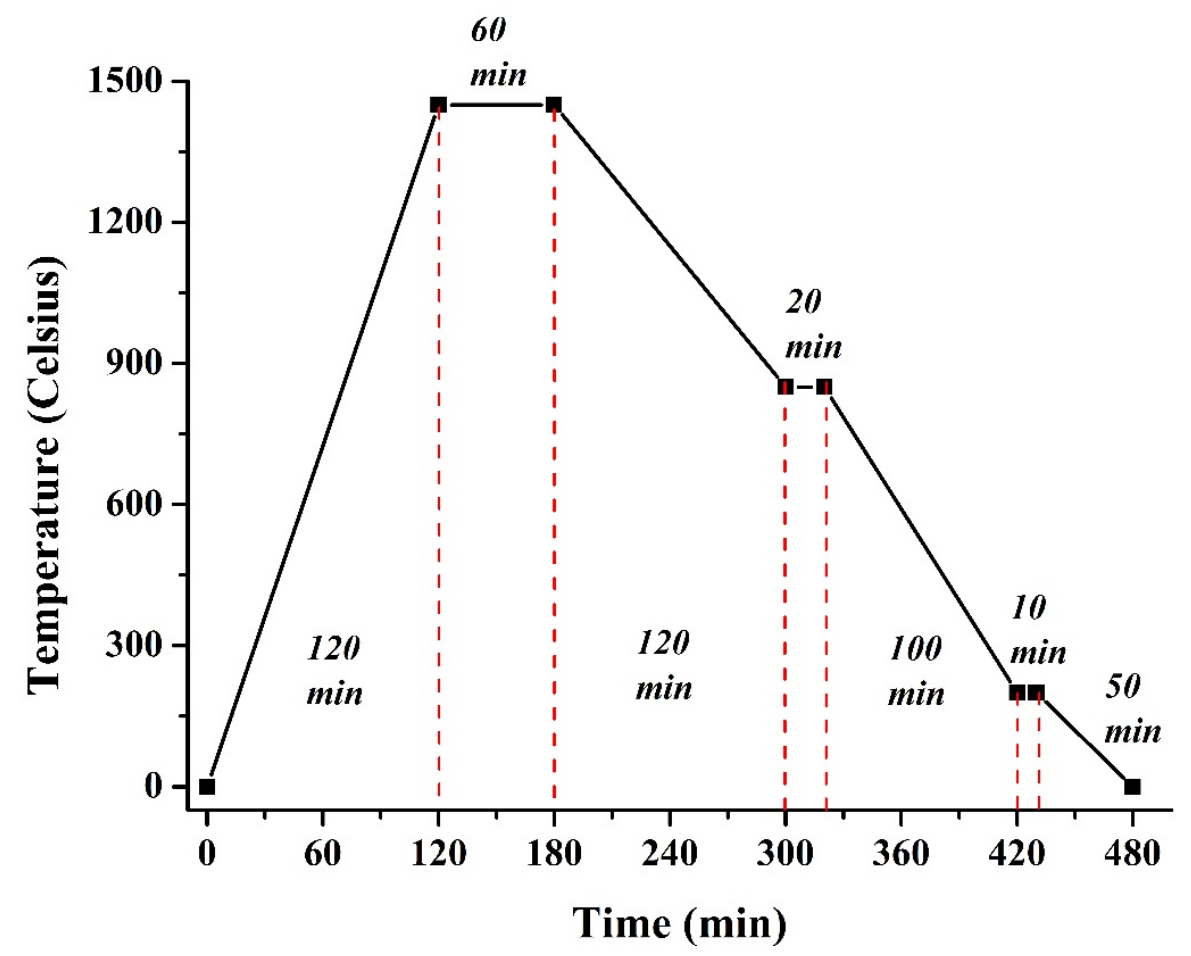

Figure 1. Zirconia sample sintering schedule.

\subsection{Surface Modification of Zirconia}

The surface of the sintered test piece was sandblasted using alumina particles with a particle size of $110 \mu \mathrm{m}$. The sample was fixed with a clamp at a distance of $10 \mathrm{~mm}$ to maintain the vertical sandblasting at 90 degrees, and a pressure of $3 \mathrm{~kg} / \mathrm{cm}^{2}$ was set to sandblast samples for $20 \mathrm{~s}$. Finally, the sample was cleaned using an ultrasound bath for $10 \mathrm{~min}$ and dried at room temperature. 


\subsection{Characterization of Zirconia}

The surface morphology of zirconia was examined using field-emission scanning electron microscopy (FESEM, JSM-6700F, JEOL, Tokyo, Japan). In this study, Au was plated on the sample surface to improve its conductivity, which helps obtain a better image resolution. In addition, image analysis software (Image J, 1.51K, National Institutes of Health, Bethesda, Maryland, MD, USA) was used to calculate the grain size. An energy dispersive spectrometer (EDS) was attached to the FESEM device to analyze the surface of the zirconia test piece qualitatively and quantitatively.

\subsection{Surface Microhardness Test}

The surface microhardness, as an important mechanical property reflecting the elastic and plastic deformations of a material, was determined. The diagonal length of the indent after a Vickers test (using a microhardness tester HMV-G 20S, SHIMADZU, Kyoto, Japan) was measured to calculate the hardness value. A force of $1.96 \mathrm{~N}$ for $15 \mathrm{~s}$ was applied to compare the effects of surface hardness and adhesion of each group of strengthened zirconia specimens.

\subsection{Surface Roughness Test (Image Pro)}

The surface roughness refers to the small spacing and unevenness of the peaks and valleys on the surface of a material. The distance between the peaks or valleys is small $(<10 \mu \mathrm{m})$ and cannot be distinguished by the naked eye; it is a microscopic geometric error. The lower the surface roughness value, the smoother the surface. In addition, the surface roughness has a significant influence on the long-term usability and reliability of the product. In this study, the average surface roughness of each group of test pieces was measured using a SURFCORDER (SE-40G, Kosaka Laboratory Ltd., Tokyo, Japan). A speed of $0.5 \mathrm{~mm} / \mathrm{s}$ and distance of $2.5 \mathrm{~mm}$ were used to measure 5 parts on the surface of the sample. Five parts were measured and the number of test pieces in each group was $N=5$.

\subsection{Preparation and Bonding of Test Pieces of Teeth}

In this experiment, teeth extracted due to trauma or correction were collected as the research samples. First, the teeth were cleaned with $75 \%$ ethanol in an ultrasonic cleaner for $60 \mathrm{~s}$, rinsed with deionized water for $30 \mathrm{~s}$, and dried. Each tooth was placed in a plastic round tubular mold (diameter $1.5 \mathrm{~cm}$, height $3 \mathrm{~cm}$ ) and filled with a transparent temporary crown resin (Tempron, GC, Tokyo, Japan). The resin was hardened for 20 min (Figure 2A). Subsequently, a slow-cutting machine was used to cut the test piece in half from the buccal side to the lingual side. The tooth surface was then polished with water sandpaper for homogenization treatment (SIC: \#800, \#1200) (Figure 2B).

A self-setting adhesive (Poly-F Plus, Dentsply, Konstanz, Germany) was used to bond each group of zirconia test pieces to the human teeth. The adhesive was mixed according to the manufacturer's instructions, and the ratio was one spoon of powder and two drops of liquid (distilled water) for $15 \mathrm{~s}$. The sample was adhered to the surface of the crown of the tooth with a square size of $0.16 \mathrm{~mm}^{2}$ and kept for $10 \mathrm{~min}$ (Figure 2C). Finally, the excess adhesive was removed, and the adhered test piece was allowed to stand for $24 \mathrm{~h}$.

\subsection{Evaluation of Bonding Strength}

In clinical practice, the bond between teeth and zirconia is damaged by bite force. Therefore, the samples were placed in the fixture and a special metal plate was used as a baffle at the top of the instrument. The strength tester (EZ-Test CE, SHIMADZU, Tokyo, Japan) was used to press it down from the crown to the apex at a speed of $0.5 \mathrm{~mm} / \mathrm{min}$ until the zirconia sample was separated from the tooth (Figure 2D). Eventually, the maximum pressure was recorded and statistical analysis performed. In addition, the fracture of the sample was evaluated through FESEM. 


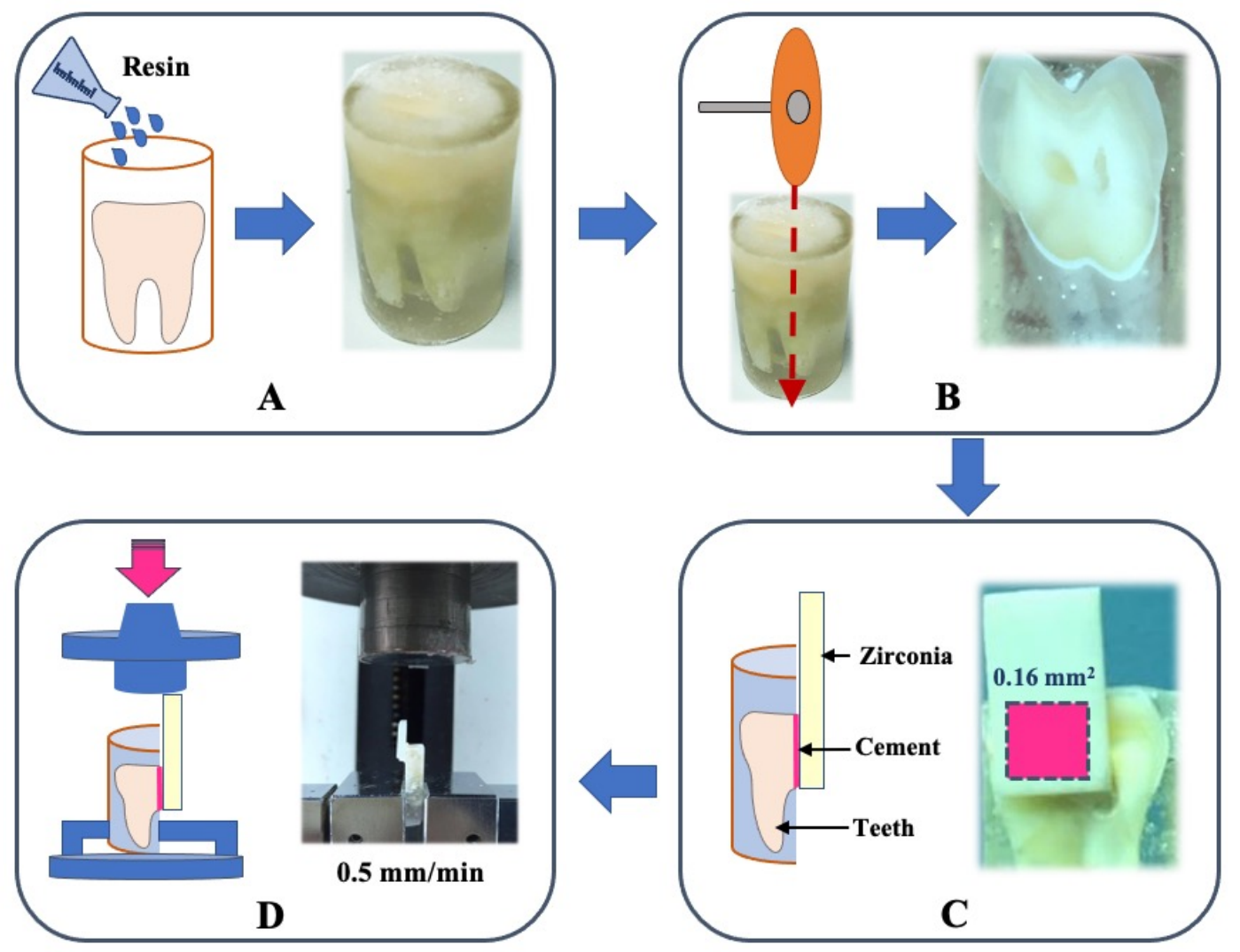

Figure 2. Compendium illustration showing the bonding of zirconia samples to teeth for the strength tester. (A) Embed; (B) Cut; (C) Bonding; (D) Strength tester.

\subsection{Aging Test}

The adhesive strength established by the adhesive deteriorates with long-term use in the oral cavity. Therefore, hot and cold cycle testing was applied to study the longterm performance of the material (aging test) [28]. We simulated the temperature change in the mouth by repeatedly soaking the samples at different temperatures to accelerate the aging time, and observed the effect of adhesion. The samples were immersed in a water tank at alternating temperatures of 5 and $55^{\circ} \mathrm{C}$ using a double tank thermal impact machine (TBN-971105, TEN Billion, Tainan, Taiwan). Each temperature was maintained for $30 \mathrm{~s}$ and the transfer time between temperature cycles was $5 \mathrm{~s}$; this was repeated for 20,000 cycles each time (total $389 \mathrm{~h}$ ). After the aging test was completed, the shear test was evaluated again.

\subsection{Statistical Analysis}

All the data are expressed as mean \pm standard deviation (SD) from four repeat samples. The data were analyzed using the JMP 13 software (Statistical Analysis System, North Carolina State University, Raleigh, NC, USA). A one-way ANOVA followed by a Tukey's HSD post hoc test was used to determine the level of significance, where $p<0.05$ was considered to be significant.

\section{Results and Discussion}

\subsection{Characterization of Zirconia}

The surface morphology of the zirconia test piece was observed using FESEM, and the grain size was calculated using image analysis software (Image Pro). Metoxit, NexxZr, Upcera, and Dentaswiss had dense and smooth surfaces formed by irregular grain boundaries. However, the surface morphology of the DeguDent sample was different from that of the other groups. In addition to an irregular grain boundary, pores were observed 
between the grain boundaries, producing a 3D surface morphology (Figure 3). The size of the grains on the surface of all zirconia samples was between 2.8 and $13 \mu \mathrm{m}^{2}$ (Figure 3). The grain size of the Upcera samples was the largest, with a statistical significance of $p<0.05$. The grain boundaries of the zirconia surfaces of the different brands mentioned above were mainly elliptical and had significant differences in terms of grain size. Figure 3 shows the zirconia surface of the alumina particles (with a particle size of $110 \mu \mathrm{m}$ ) after sandblasting. The results show that the grain boundary lattice structure on the surface was completely destroyed, with irregular and undulating fragments. This is similar to that reported in the literature, where the original crystal morphology was damaged by the impact of alumina particles [29]. However, the surface structure of the DeguDent test piece was not destroyed, presumably because of its 3D surface morphology. The alumina particles cannot enter during the sandblasting process, and thus, the original appearance is retained. Therefore, after sandblasting, the surface of zirconia is destroyed, producing a rougher surface morphology.
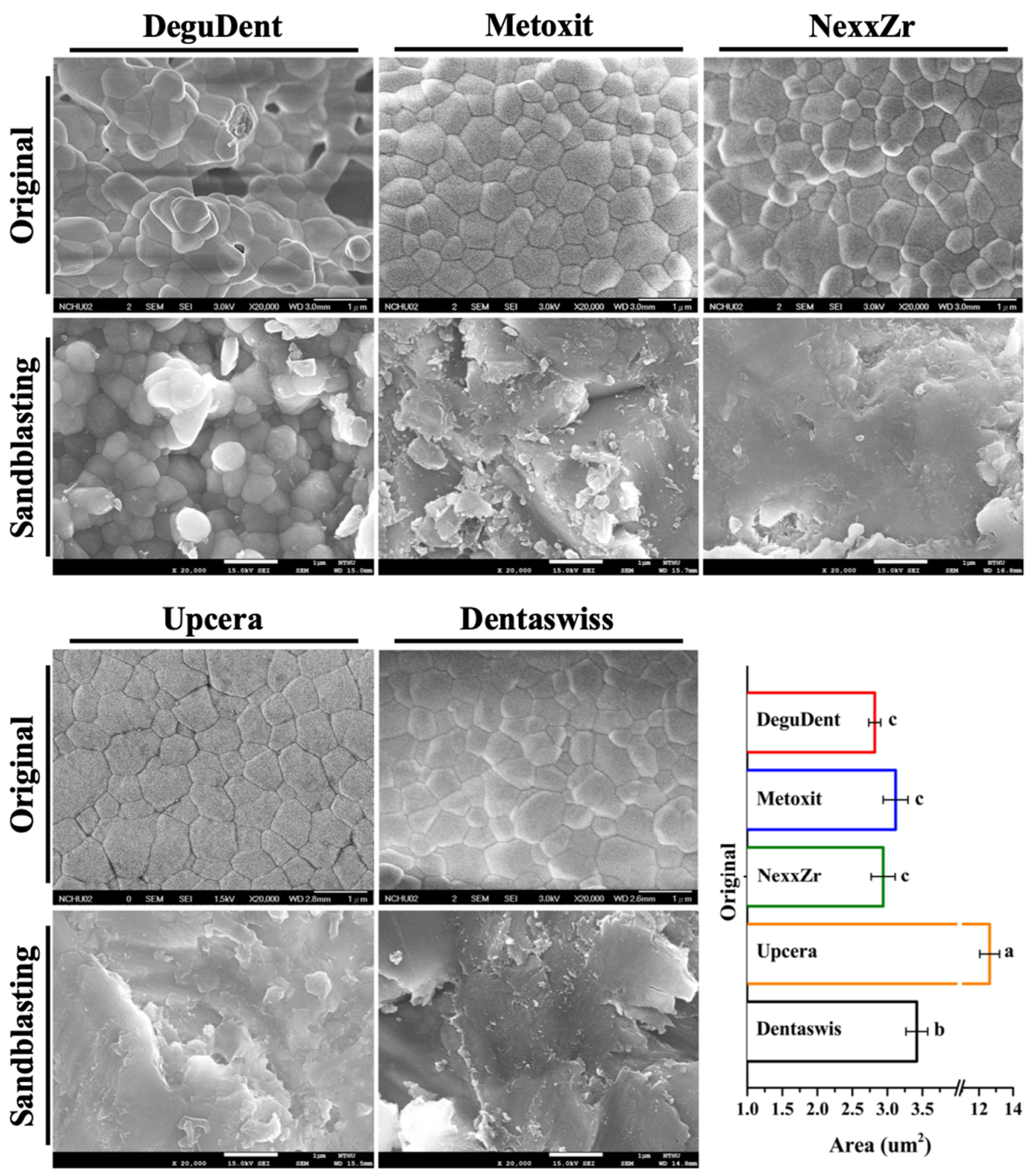

Figure 3. The surface morphology of zirconia before and after sandblasting. Means with different letters were significantly different $(p<0.05$, mean $\pm \mathrm{SD}, n=4)$. 


\subsection{Surface Microhardness Test}

Compared to other hardness tests, the Vickers hardness (-) test provides a clear hardness value without having to change the indenter for materials with different hardness. A square indentation contour has clear edges and is easy to measure. It is often applied to thin test materials. Therefore, the surface hardness of zirconia was evaluated using Vickers hardness in this study. The results show that the hardness of the zirconia sample before sandblasting was between $\mathrm{HV}_{0.2}=1337$ and $\mathrm{HV}_{0.2}=1734$ (Figure 4A). DeguDent exhibited the highest hardness, followed by Metoxit, with a significant difference $(p<0.05)$. There was no difference between the other groups $(p>0.05)$. The surface hardness of the zirconia specimens of different brands tended to decrease after sandblasting, and the surface hardness values were between $\mathrm{HV}_{0.2}=741.75$ and $\mathrm{HV}_{0.2}=973.0$ (Figure 4B). The results are similar to those of the original samples. The rate of decrease in the hardness of the surface of each group of samples was approximately 54\%-64\% (Figure 4B). DeguDent had the lowest reduction in hardness value. The decrease in the Vickers hardness value can be explained by the surface morphology of the sample; the crystal structure on the surface was destroyed after sandblasting, resulting in a decrease in the value of surface hardness.
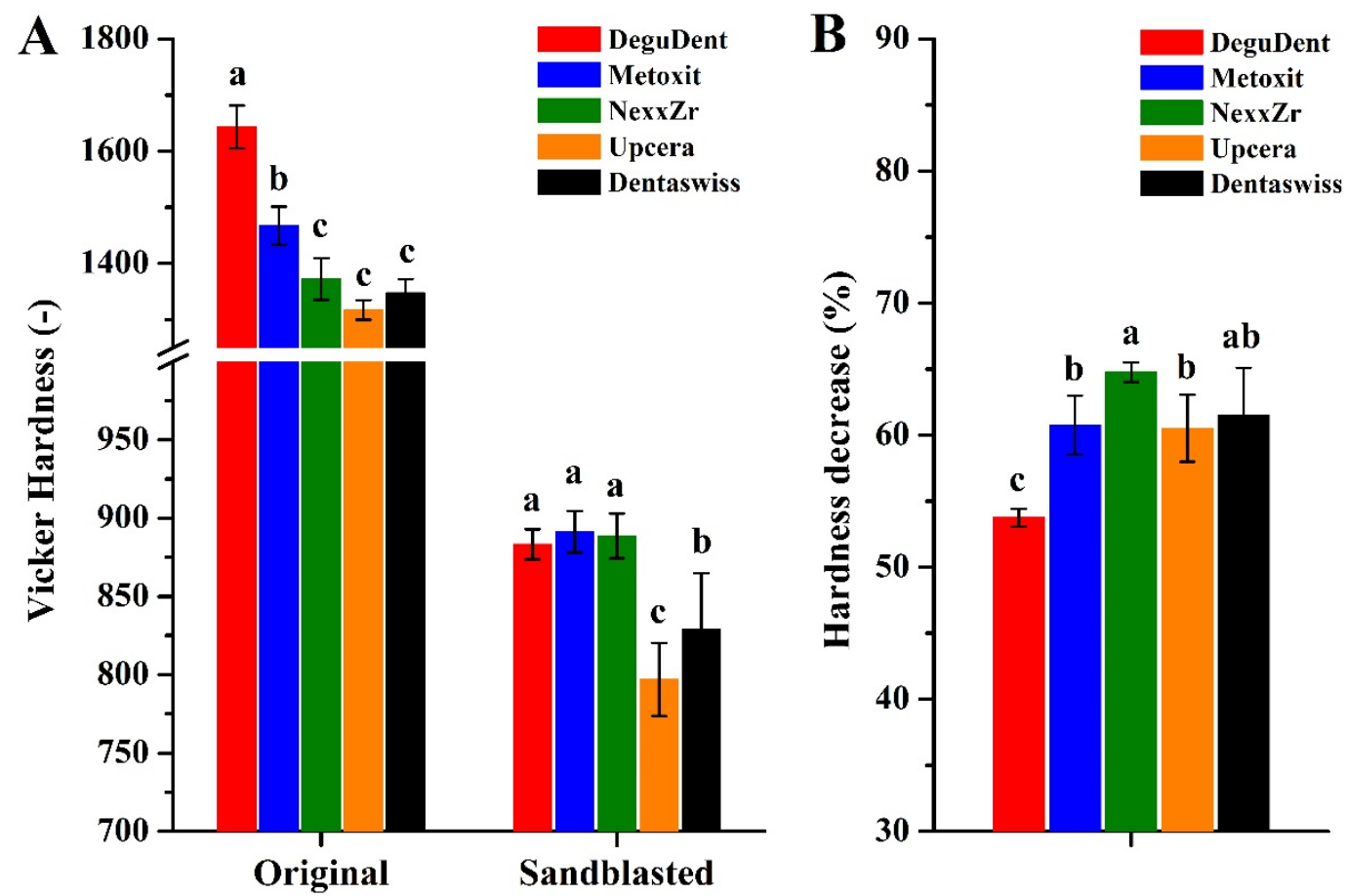

Figure 4. The surface microhardness of zirconia samples of different brands: (A) Sample before and after sandblasting; (B) Sandblasting compares the drop of samples. Means with different letters were significantly different $(p<0.05$, mean $\pm \mathrm{SD}, n=4)$.

\subsection{Surface Roughness Test}

In clinics, dental technicians often use sandblasting steps to improve the bonding effect between zirconia abutment and metal crowns. In this study, the sample was subjected to surface treatment using alumina particles with a diameter of $110 \mu \mathrm{m}$ to improve the roughness of the oxidation surface. The centerline average roughness ( $\mathrm{Ra})$, mean peak to valley height of roughness profile ( $\mathrm{Rz})$, and maximum height of the profile (Rmax) on the surface of the zirconia sample were measured using a surface roughness meter. The results showed that the values of $\mathrm{Ra}, \mathrm{Rz}$, and $\mathrm{Rmax}$ of the samples were in the ranges of 0.25-0.55, 1.7-4.0, and 2.6-5.5 $\mu \mathrm{m}$ (Figure 5), respectively. There were significant differences between the above groups $(p<0.05)$. All the zirconia samples exhibited a significant increase in surface roughness after sandblasting. This result is similar to that reported in the literature. The roughness obtained after sandblasting was approximately $0.5 \mu \mathrm{m}$ [30]. 
The surface roughness results were consistent with the surface topography results. The original flat zirconia surface was destroyed after sandblasting, resulting in a high surface roughness. In addition, the DeguDent sample exhibited high surface roughness because of the increased depth of field after sandblasting. Compared to other zirconia specimens, DeguDent exhibited the best surface roughness effect after sandblasting. A rough zirconia surface helps the resin adhesive to provide a wider contact area and micropores, thereby improving the bonding strength [13].
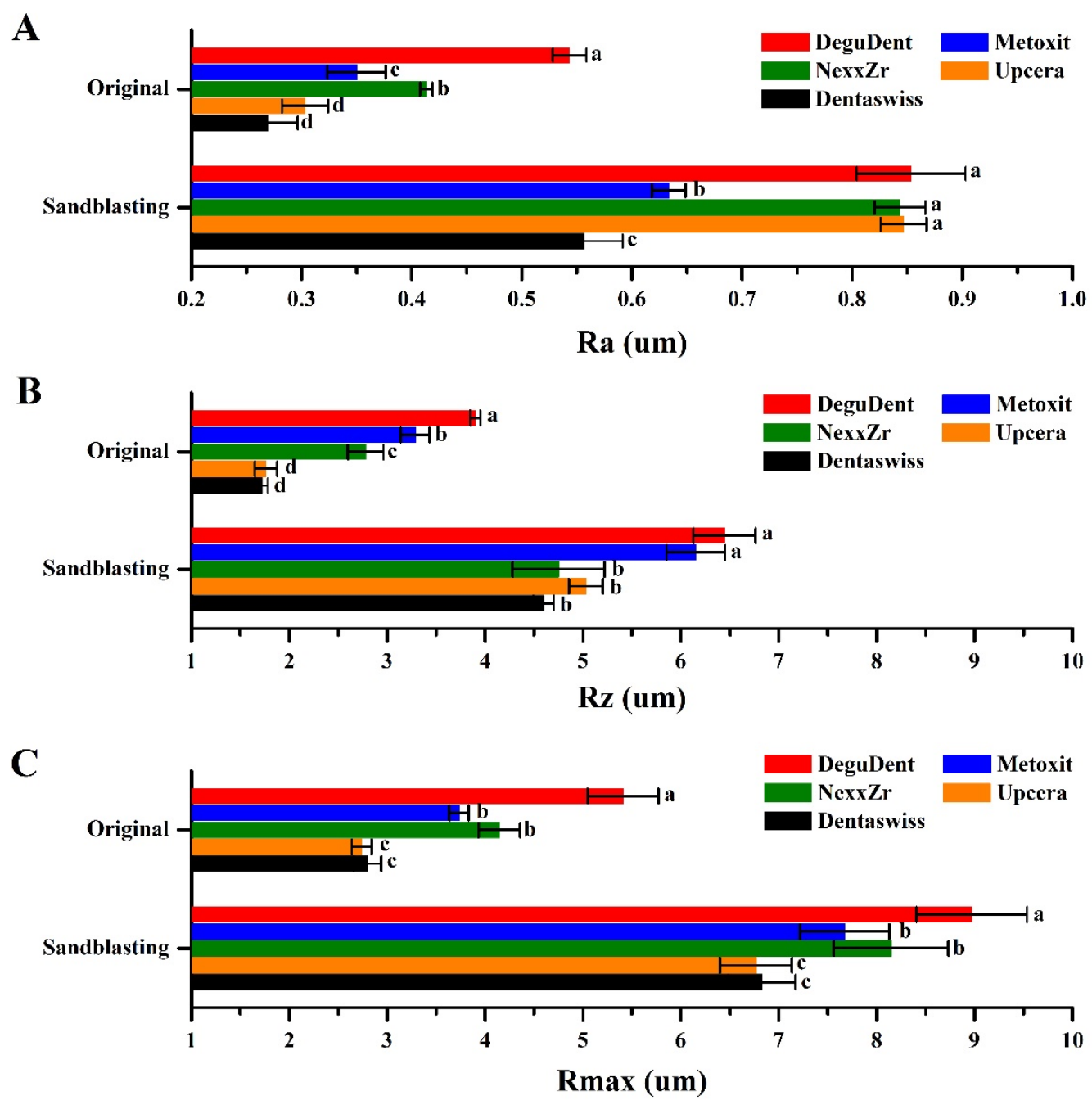

D

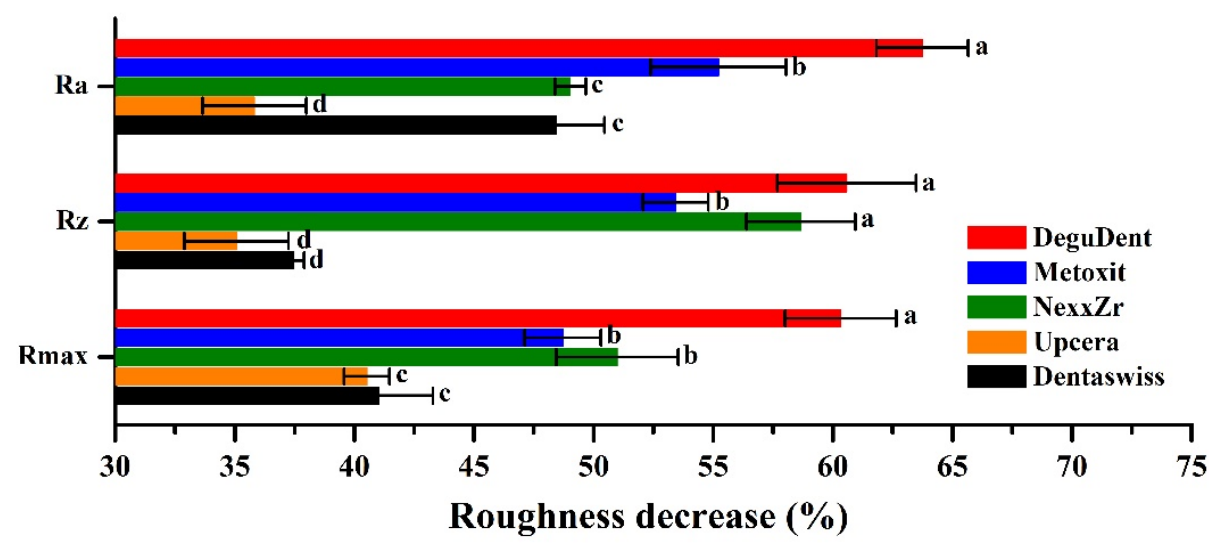

Figure 5. The surface roughness of different brands of zirconia samples (A) Ra, (B) Rz, (C) Rmax and (D) Cpmpare. Means with different letters were significantly different $(p<0.05$, mean $\pm \mathrm{SD}, n=4)$. 


\subsection{Surface Element Analysis}

The surface of each zirconia test piece was analyzed qualitatively and quantitatively using an X-ray EDS. In addition to oxygen and zirconium, other elements were observed on the surface of the zirconia samples (Figure 6A). The EDS results of all the samples were consistent with the original composition, mainly oxygen and zirconium. Carbon was found on the original surface of DeguDent, NexxZr, and Upcera. The ratio ranges from 11.02 atomic\% to 40.09 atomic\%. This may be due to the addition of the zirconia disc during production, or the adsorption of carbon dioxide or tiny carbon particles from the air during storage. After sandblasting, aluminum was observed on the surfaces of all the samples (Figure 6). The results confirmed that sandblasting treatment could help effectively coat aluminum on the surface of zirconia. A study has shown that only a small amount of alumina particles on the surface of zirconia do not seem to damage the resin bond [31]. Hallmann et al. also reported that the use of alumina particles under different blasting pressures may give better results than using silica coated alumina particles [29]. Therefore, the residual aluminum on the surface may facilitate bonding.
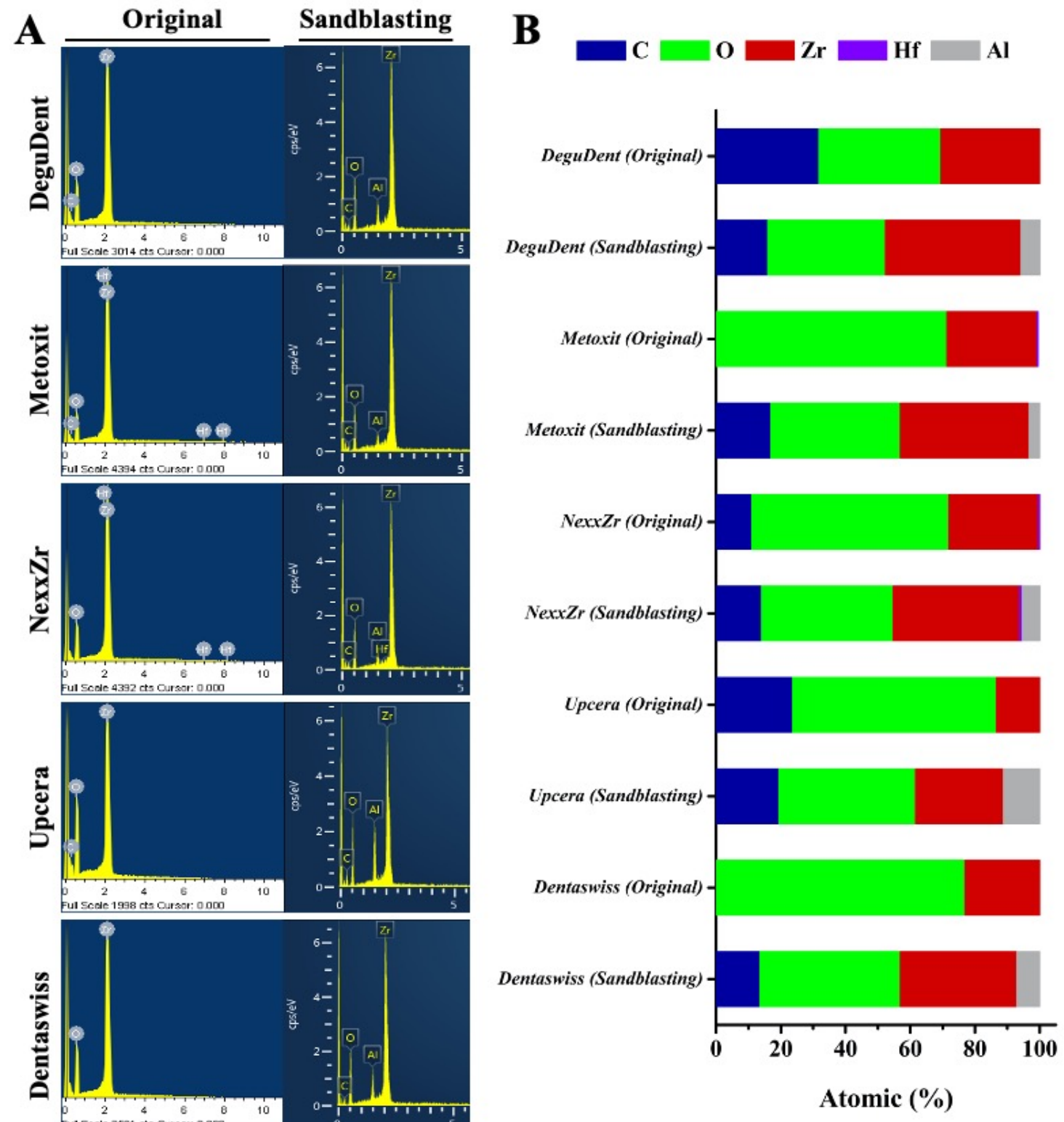

Figure 6. Surface element analysis of zirconia samples of different brands by EDS. (A) Qualitatively; (B) Quantitatively. 


\subsection{Evaluation of Bonding Strength and Aging Test}

FESEM was used to evaluate the adhesion of the zirconia sample to the tooth slice, and then a shear test was performed to observe the fracture of the adhesive on the zirconia test piece (Figure 7). The DeguDent, Metoxit, NexxZr, and Dentaswiss groups are flat flake surfaces with minor cracks and small particles. These flat sheet-like structures of inconsistent sizes are left behind by the fracture of the resin adhesives. In the Upcera group, an almost irregular particle morphology was clearly visible. This is because of poor bonding between the adhesive and the zirconia surface, which results in fractured surfaces between the two. According to the literature, the fracture is due to improper adhesion between the adhesive and the ceramic [32]. The surface was modified by sandblasting with alumina particles to facilitate better adhesion to the teeth before a shear test was carried out. The remaining adhesive could be observed with the naked eye on the test pieces of each group. FESEM was used to observe the surface morphology of the fracture surface of the adhesive. There were resin residues on the surfaces of all groups. In particular, the pores on the surface of the Upcera group were covered with the adhesive, indicating that there was more surface bonding between the resin and zirconia. Finally, the surface of the zirconia test piece was almost intact with the resin residue after sandblasting and aging treatment.

However, after the sample was repeatedly immersed in a water bath at 5 and $55^{\circ} \mathrm{C}$ for 20,000 cycles of heat and cold, cracks appeared on the surface of the resin adhesive due to hot and cold stimulation (Figure 7). Nevertheless, the FESEM images show that the surface sandblasting of zirconia improves bonding with the resin adhesive. Resin adhesives crack because of hot and cold stimulation and cause structural damage to zirconia. In addition, the FESEM images of each group of shear tests showed that the bonding strength between the adhesive and the teeth was relatively low. Moreover, most of the surfaces separated from the teeth appeared smooth, and the adhesive hardly penetrated the tooth cavities. The cause of adhesion failure is the poor bonding between the adhesive and the tooth surface. Therefore, the teeth should also be treated during the adhesive procedure to improve the bonding between the adhesive and teeth [33].

The strength of the zirconia test piece was calculated after shear testing (Figure 8A). The results showed that the shear strength of the zirconia test piece ranged from 6.1 to $10.5 \mathrm{MPa}$. Among them, DeguDent was the highest with a statistical difference $(p<0.05)$. The shear strength of the zirconia sample after sandblasting ranged from 7.0 to $13.5 \mathrm{MPa}$. The shear strength of the test pieces after the aging test ranged from 3.5 to $5.5 \mathrm{MPa}$. These two trends are consistent with the results of the original zirconia samples, with DeguDent showing the highest results for both $(p<0.05)$. The results of sandblasting and aging tests on the surfaces of different brands of zirconia showed that the sandblasting treatment effectively improved the bonding between the zirconia and the resin adhesive (Figure 8B). Previous studies have shown that alumina with a particle size of $50 \mu \mathrm{m}$ can be used to adjust the ceramic surface by sandblasting it at an operating distance of $0.25 \mathrm{MPa}$. Increasing the surface roughness to improve the bond strength yielded results similar to those reported in this study [34,35].

The surface roughness of zirconia increased after sandblasting, and this increased the mechanical interlocking area. Therefore, an appropriate micron level roughness can increase the mechanical interlocking effect [36]. A study has also shown that surface treatment can remove surface dirt and improve wettability, so that the resin binder can flow into the rough surface of zirconia more easily [37]. However, the resin adhesive stimulated by hot and cold cycles destroyed the internal structure of the zirconia. As a result, the shear strength was significantly reduced (Figure 8B). Syed Rashid Habib et al. reported that the shear bond strength of zirconia repaired using various methods and adhesive systems is approximately in the range of 9.77-13.44 MPa. The results show that the adhesive will also affect the bond strength [38]. Therefore, the bonding effect of the adhesive needs to be investigated in future research. 

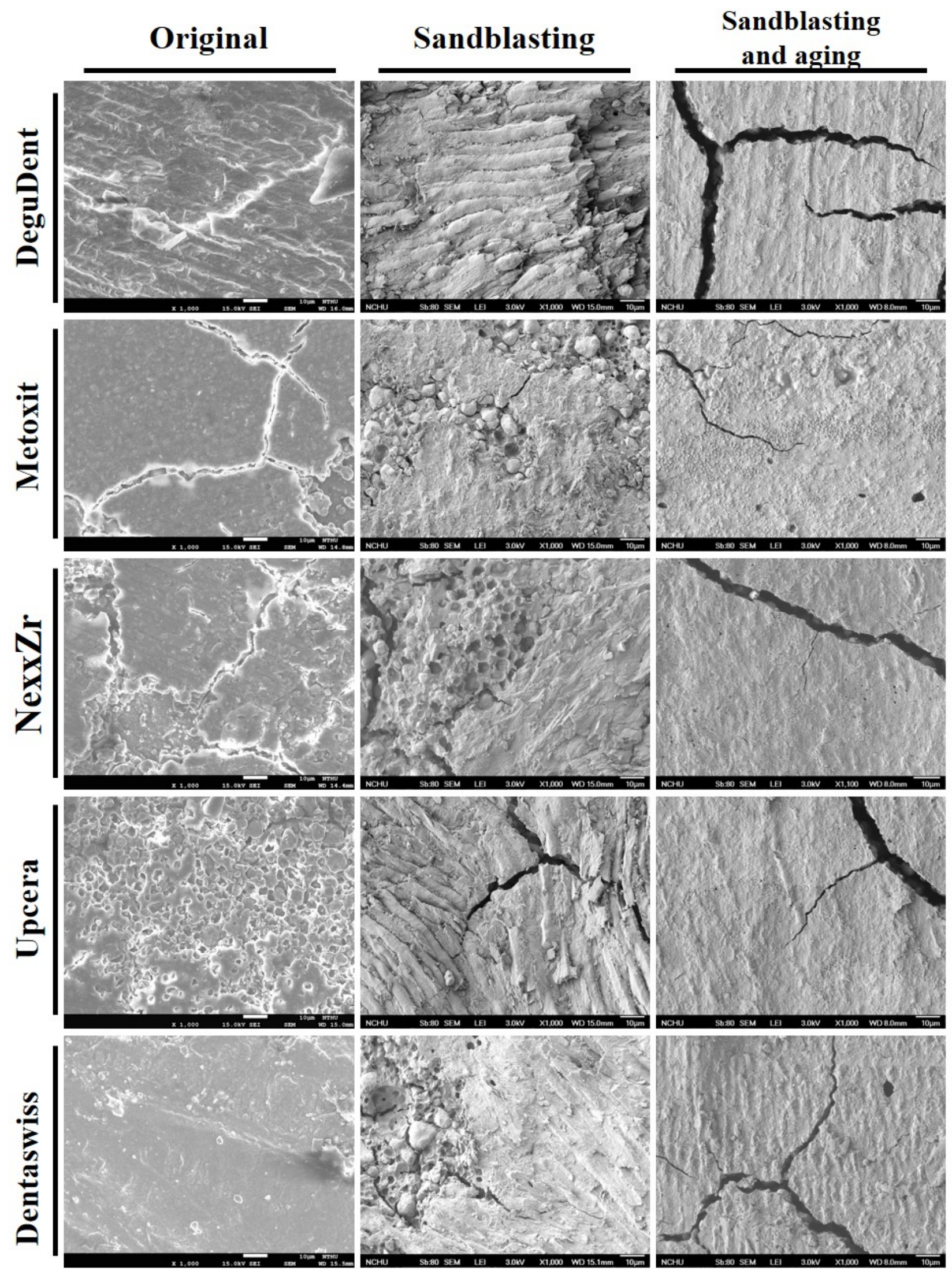

Figure 7. The fracture surface morphology of zirconia and tooth adhesion after sandblasting and aging treatment. 

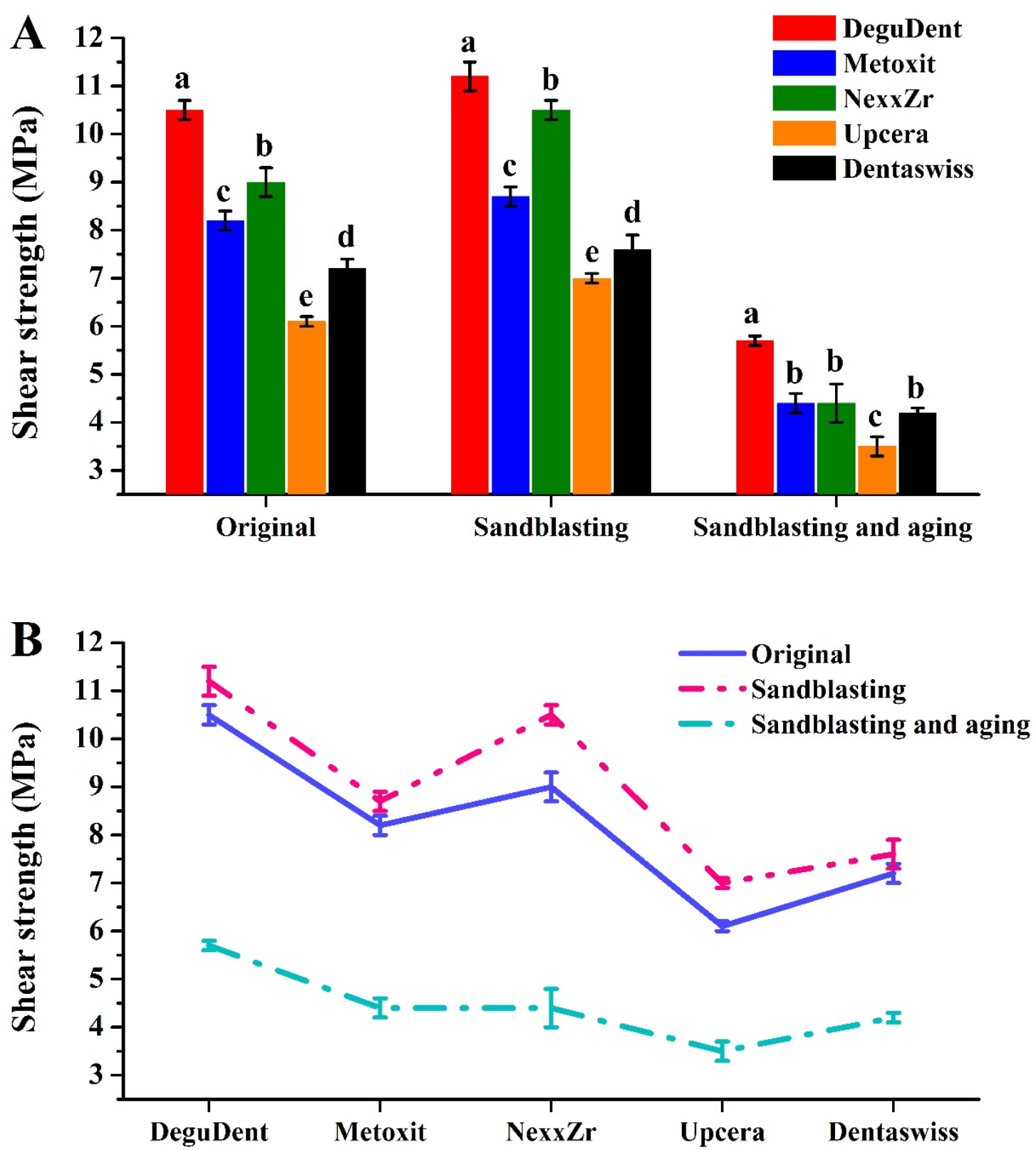

Figure 8. Comparison of bond strength between different zirconia samples and teeth after the aging test: (A) The effect of various surface treatments on different brands of zirconia; (B) The changing trend of the shear strength of different surface treatments of a single brand of zirconia. Means with different letters were significantly different $(p<0.05$, mean $\pm \mathrm{SD}, n=4)$.

In addition, this study explored the influence of the change in the morphology of the zirconia surface treatment on the bonding effect. The results showed a positive correlation between the surface roughness and the shear strength (Figure 9A), whereas the microhardness of the surface was inversely correlated with the shear strength (Figure 9B). This study explored the influence of the bond strength of zirconia with teeth, including (1) grain size, (2) surface microhardness, (3) surface roughness, and (4) surface elements. The above results indicate that the choice of zirconia brand in clinical practice is not the most important factor influencing the bonding strength, but rather, increasing the surface roughness can improve the bonding effect. Therefore, it is recommended that sandblasting or other methods are used in clinical practice to improve the surface roughness of zirconia and hence promote adhesion to teeth. 

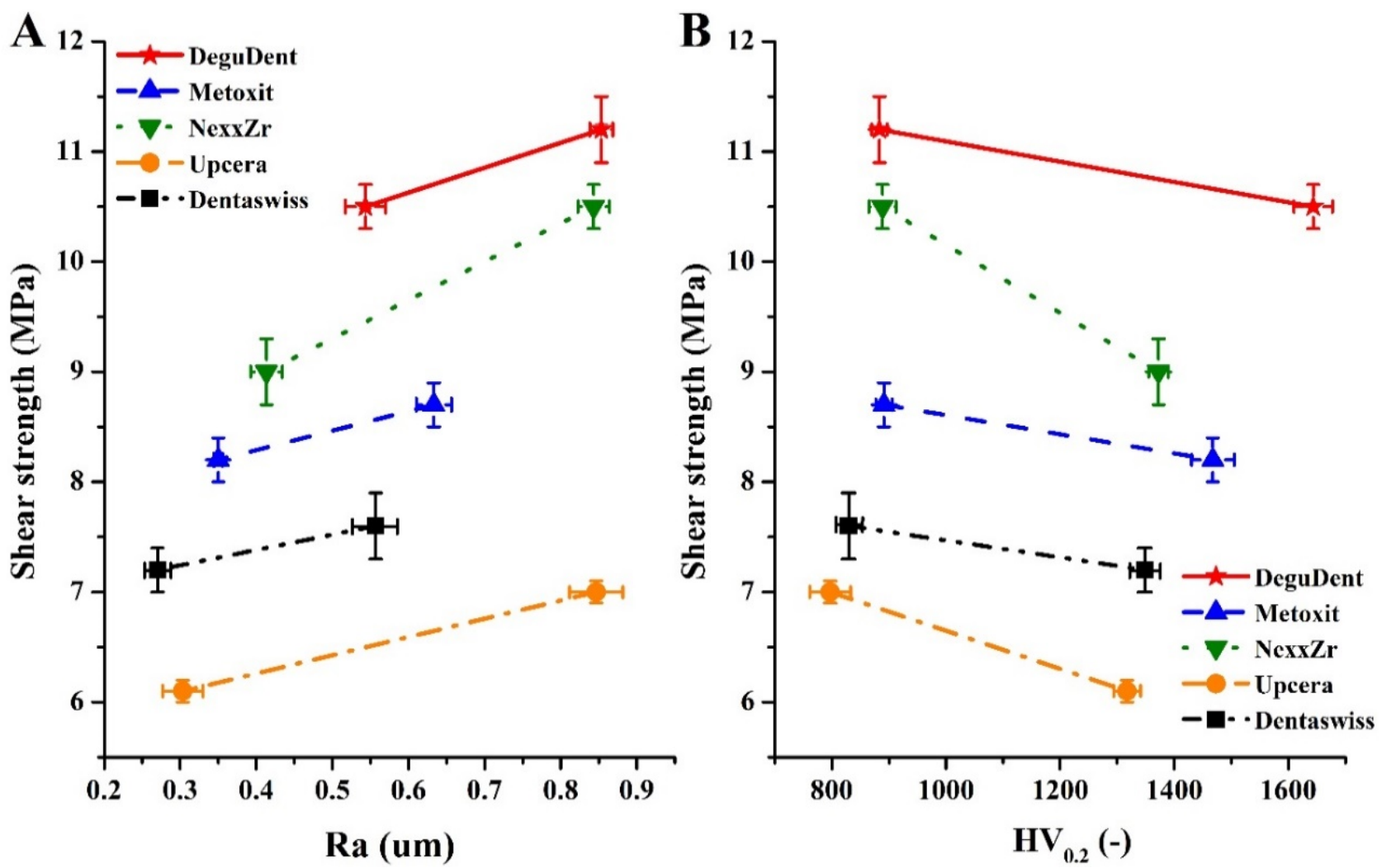

Figure 9. The bond strength between different zirconia samples and teeth after the aging test $(p<0.05$, mean $\pm \mathrm{SD}, n=4)$ : (A) Comparison of shear strength and average roughness; (B) Comparison of shear strength and Vickers hardness (-).

\section{Conclusions}

In this study, different brands of zirconia were explored and evaluated for use as zirconia posts. The effect of surface treatment on the bond strength of zirconia was evaluated by sandblasting. The results showed improvement in the surface roughness of the sandblasted zirconia samples. After the aging test (20,000 hot and cold cycles), the bonding strength of each group of zirconia samples showed a downward trend. By analyzing FESEM images of samples subjected to shear tests, it was found that the fractured surface was located between the resin and the tooth. This shows that the bond of zirconia is not damaged after surface treatment. Therefore, the main factor affecting the bonding of zirconia was found to be the surface roughness. In the future, we will continue to explore the effects of different sandblasting and mixing methods on the bonding of zirconia. We hope to provide valuable information for better clinical treatments.

Author Contributions: S.-C.L. is the core first author for contributions to the analysis and interpretation of data, drafting of the manuscript, and critical revision of the manuscript; W.-C.L. and T.-C.H. carried out the experiment; M.Y. and C.-M.T. were the corresponding authors and contributed to the design and implementation of the research, analysis of the results, and writing of the manuscript. All authors have read and agreed to the published version of the manuscript.

Funding: This research received no external funding.

Institutional Review Board Statement: Not applicable.

Informed Consent Statement: Not applicable.

Data Availability Statement: Not applicable.

Conflicts of Interest: There are no conflict to declare. 


\section{References}

1. Imirzalioglu, P.; Alaaddinoglu, E.; Yilmaz, Z.; Oduncuoglu, B.; Yilmaz, B.; Rosenstiel, S. Influence of recasting different types of dental alloys on gingival fibroblast cytotoxicity. J. Prosthet. Dent. 2012, 107, 24-33. [CrossRef]

2. Li, R.; Zhou, H.; Wei, W.; Wang, C.; Sun, Y.C.; Gao, P. Effects of mechanical and chemical pretreatments of zirconia or fiber posts on resin cement bonding. PLOS ONE 2015, 10, e0129690.

3. Tanimoto, Y. Dental materials used for metal-free restorations: Recent advances and future challenges. J. Prosthodont. Res. 2015, 59, 213-215. [CrossRef] [PubMed]

4. Manicone, P.F.; Rossi Iommetti, P.; Raffaelli, L. An overview of zirconia ceramics: Basic properties and clinical applications. J. Dent. 2007, 35, 819-826. [CrossRef] [PubMed]

5. Sailer, I.; Pjetursson, B.E.; Zwahlen, M.; Hämmerle, C.H. A systematic review of the survival and complication rates of all-ceramic and metal-ceramic reconstructions after an observation period of at least 3 years. Part II: Fixed dental prostheses. Clin. Oral Implants Res. 2007, 18, 86-96. [CrossRef] [PubMed]

6. Martino, N.; Truong, C.; Clark, A.E.; O’Neill, E.; Hsu, S.-M.; Neal, D.; Esquivel-Upshaw, J.F. Retrospective analysis of survival rates of post-and-cores in a dental school setting. J. Prosthet. Dent. 2020, 123, 434-441. [CrossRef]

7. Miyazaki, T.; Nakamura, T.; Matsumura, H.; Ban, S.; Kobayashi, T. Current status of zirconia restoration. J. Prosthodont. Res. 2013, 57, 236-261. [CrossRef]

8. Mattiello, R.D.L.; Coelho, T.M.K.; Insaurralde, E.; Coelho, A.A.K.; Terra, G.P.; Kasuya, A.V.B.; Favarão, I.N.; Gonçalves, L.d.S.; Fonseca, R.B. A review of surface treatment methods to improve the adhesive cementation of zirconia-based ceramics. ISRN Biomater. 2013, 2013, 185376. [CrossRef]

9. Cavalcanti, A.N.; Foxton, R.M.; Watson, T.F.; Oliveira, M.T.; Giannini, M.; Marchi, G.M. Bond strength of resin cements to a zirconia ceramic with different surface treatments. Oper. Dent. 2009, 34, 280-287.

10. Almufleh, B.S.; Aleisa, K.I.; Morgano, S.M. Effect of surface treatment and type of cement on push-out bond strength of zirconium oxide posts. J. Prosthet. Dent. 2014, 112, 957-963. [CrossRef]

11. Gomes, A.L.; Castillo-Oyague, R.; Lynch, C.D.; Montero, J.; Albaladejo, A. Influence of sandblasting granulometry and resin cement composition on microtensile bond strength to zirconia ceramic for dental prosthetic frameworks. J. Dent. 2013, 41, 31-41. [CrossRef] [PubMed]

12. Grigore, A.; Spallek, S.; Petschelt, A.; Butz, B.; Spiecker, E.; Lohbauer, U. Microstructure of veneered zirconia after surface treatments: A TEM study. Dent. Mater. 2013, 29, 1098-1107. [CrossRef] [PubMed]

13. Lin, Y.; Song, X.; Chen, Y.; Zhu, Q.; Zhang, W. Effect of Er: YAG laser irradiation on bonding property of zirconia ceramics to resin cement. Photomed. Laser Surg. 2013, 31, 619-625. [CrossRef] [PubMed]

14. Hallmann, L.; Ulmer, P.; Lehmann, F.; Wille, S.; Polonskyi, O.; Johannes, M.; Kobel, S.; Trottenberg, T.; Bornholdt, S.; Haase, F.; et al. Effect of surface modifications on the bond strength of zirconia ceramic with resin cement resin. Dent. Mater. 2016, 32, 631-639. [CrossRef]

15. Casucci, A.; Mazzitelli, C.; Monticelli, F.; Toledano, M.; Osorio, R.; Osorio, E.; Papacchini, F.; Ferrari, M. Morphological analysis of three zirconium oxide ceramics: Effect of surface treatments. Dent. Mater. 2010, 26, 751-760. [CrossRef]

16. Zandparsa, R.; Talua, N.A.; Finkelman, M.D.; Schaus, S.E. An in vitro comparison of shear bond strength of zirconia to enamel using different surface treatments. J. Prosthodont. 2014, 23, 117-123. [CrossRef]

17. Aboushelib, M.N.; Feilzer, A.J.; Kleverlaan, C.J. Bonding to zirconia using a new surface treatment. J. Prosthodont. 2010, 19, 340-346. [CrossRef]

18. Chintapalli, R.K.; Mestra Rodriguez, A.; Garcia Marro, F.; Anglada, M. Effect of sandblasting and residual stress on strength of zirconia for restorative dentistry applications. J. Mech. Behav. Biomed. Mater. 2014, 29, 126-137. [CrossRef]

19. Flamant, Q.; Anglada, M. Hydrofluoric acid etching of dental zirconia. Part 2: Effect on flexural strength and ageing behavior. J. Eur. Ceram. Soc. 2016, 36, 135-145. [CrossRef]

20. Liu, D.; Tsoi, J.K.; Matinlinna, J.P.; Wong, H.M. Effects of some chemical surface modifications on resin zirconia adhesion. J. Mech. Behav. Biomed. Mater. 2015, 46, 23-30. [CrossRef]

21. da Silva, E.M.; Miragaya, L.; Sabrosa, C.E.; Maia, L.C. Stability of the bond between two resin cements and an yttria-stabilized zirconia ceramic after six months of aging in water. J. Prosthet. Dent. 2014, 112, 568-575. [CrossRef]

22. Inokoshi, M.; Kameyama, A.; De Munck, J.; Minakuchi, S.; Van Meerbeek, B. Durable bonding to mechanically and/or chemically pre-treated dental zirconia. J. Dent. 2013, 41, 170-179. [CrossRef]

23. Liu, D.; Pow, E.H.; Tsoi, J.K.; Matinlinna, J.P. Evaluation of four surface coating treatments for resin to zirconia bonding. J. Mech. Behav. Biomed. Mater. 2014, 32, 300-309. [CrossRef]

24. Tokar, E.; Polat, S.; Ozturk, C. Repair bond strength of composite to Er,Cr:YSGG laser irradiated zirconia and porcelain surfaces. Biomed. J. 2019, 42, 193-199. [CrossRef]

25. Rekow, E.D.; Silva, N.R.F.A.; Coelho, P.G.; Zhang, Y.; Guess, P.; Thompson, V.P. Performance of dental ceramics: Challenges for improvements. J. Dent. Res. 2011, 90, 937-952. [CrossRef] [PubMed]

26. Lebon, N.; Tapie, L.; Vennat, E.; Mawussi, B. Influence of CAD/CAM tool and material on tool wear and roughness of dental prostheses after milling. J. Prosthet. Dent. 2015, 114, 236-247. [CrossRef] [PubMed]

27. Kastyl, J.; Chlup, Z.; Stastny, P.; Trunec, M. Machinability and properties of zirconia ceramics prepared by gelcasting method. Adv. Appl. Ceram. 2020, 119, 252-260. [CrossRef] 
28. Al-Akhali, M.; Al-Dobaei, E.; Wille, S.; Mourshed, B.; Kern, M. Influence of elapsed time between airborne-particle abrasion and bonding to zirconia bond strength. Dent. Mater. 2021, 37, 516-522. [CrossRef]

29. Hallmann, L.; Ulmer, P.; Reusser, E.; Hämmerle, C.H. Effect of blasting pressure, abrasive particle size and grade on phase transformation and morphological change of dental zirconia surface. Surf. Coat. Technol. 2012, 206, 4293-4302. [CrossRef]

30. Bitencourt, S.B.; dos Santos, D.M.; da Silva, E.V.F.; Barão, V.A.R.; Rangel, E.C.; da Cruz, N.C.; de Souza, G.M.; Goiato, M.C.; Pesqueira, A.A. Characterisation of a new plasma-enhanced film to improve shear bond strength between zirconia and veneering ceramic. Mater. Sci. Eng. C 2018, 92, 196-205. [CrossRef] [PubMed]

31. Kwon, S.-M.; Min, B.K.; Kim, Y.K.; Kwon, T.-Y. Influence of sandblasting particle size and pressure on resin bonding durability to zirconia: A residual stress study. Materials 2020, 13, 5629. [CrossRef] [PubMed]

32. Itthipongsatorn, N.; Srisawasdi, S. Dentin microshear bond strength of various resin luting agents to zirconia-reinforced lithium silicate ceramics. J. Prosthet. Dent. 2020, 124, 237.e1-237.e7. [CrossRef]

33. Franz, A.; Winkler, O.; Lettner, S.; Öppinger, S.; Hauser, A.; Haidar, M.; Moritz, A.; Watts, D.C.; Schedle, A. Optimizing the fitting-surface preparation of zirconia restorations for bonding to dentin. Dent. Mater. 2021, 37, 464-476. [CrossRef] [PubMed]

34. Aung, S.S.M.P.; Takagaki, T.; Lyann, S.K.; Ikeda, M.; Inokoshi, M.; Sadr, A.; Nikaido, T.; Tagami, J. Effects of alumina-blasting pressure on the bonding to super/ultra-translucent zirconia. Dent. Mater. 2019, 35, 730-739. [CrossRef]

35. Cebe, M.; Polat, S.; Cebe, F.; Tuncdemir, M.; Isman, E. Bonding performance of two newly developed self-adhering materials between zirconium and dentin. Niger. J. Clin. Pract. 2015, 18, 221-226. [CrossRef]

36. Silva, G.A.F.; da Luz, E.C.; dos Reis Goyatá, F.; da Silva Concilio, L.R.; Neves, A.C.C.; Vitti, R.P.; Cunha, L.G. Influence of surface treatments on topography and bond strength of densely-sintered zirconium-oxide ceramic. Ceram. Int. 2016, 42, 8136-8139. [CrossRef]

37. Yang, B.; Barloi, A.; Kern, M. Influence of air-abrasion on zirconia ceramic bonding using an adhesive composite resin. Dent. Mater. 2010, 26, 44-50. [CrossRef] [PubMed]

38. Habib, S.R.; Bajunaid, S.; Almansour, A.; AbuHaimed, A.; Almuqrin, M.N.; Alhadlaq, A.; Zafar, M.S. Shear bond strength of veneered zirconia repaired using various methods and adhesive systems: A comparative study. Polymers 2021, 13, 910. [CrossRef] 